\title{
HST IN SEARCH OF BINARIES AMONG FAINT MEMBERS OF THE HYADES CLUSTER
}

\author{
O. FRANZ, K.J. KREIDL, L.H. WASSERMAN, \\ A.J. BRADLEY, G.F. BENEDICT, R.L. DUNCOMBE, \\ P.D. HEMENWAY, W.H. JEFFERYS, B. McARTHUR, \\ E. NELAN, P.J. SHELUS, D. STORY, \\ A.L. WHIPPLE, L.W. FREDRICK and W.F. van ALTENA
}

\begin{abstract}
The HST Astrometry Science Team is using the Fine Guidance Sensors (FGS) in the Transfer Function (TF) Scan mode to search for binaries among the faint members of the Hyades cluster. To date (March 1994), nine binaries have been discovered among 24 stars examined. The closest pair (total $\mathrm{V}=13.5$ ) has a separation of 0.051 arcsec; the faintest ( $\mathrm{sep}=0.287$ arcsec) has magnitudes $\mathrm{V}=15.0$ and 16.5 ; neither object posed a challenge to the capabilities of FGS. For another pair, two observations 152 days apart show a 13 deg change in position angle, indicating rapid orbital motion. One decade should suffice to define the orbit with angular dimensions of sub-millisecond of arc accuracy.

Clearly, this work will soon permit mass determinations for low-luminosity members of the Hyades cluster. Moreover, information on the frequency of binaries will provide insight into the role of duplicity in star formation and in the dynamic evolution of the cluster. To be truly useful, a census of binaries in the Hyades (and other clusters) must ultimately reach cluster members fainter than those currently under investigation, requiring astrometry with sub-millisecond of arc accuracy at near-infrared wavelengths.
\end{abstract}

